\title{
AlmaMater: património bibliográfico e identidade na Universidade de Coimbra
}

\section{AlmaMater: bibliographic heritage and identity at the University of Coimbra}

Ana Eva Miguéis ${ }^{1}$

\section{RESUMO}

A AlmaMater é a biblioteca digital de fundo antigo da Universidade de Coimbra, apresentada publicamente em julho de 2010. A AlmaMater congrega várias coleções digitais representativas da Biblioteca Geral da Universidade de Coimbra, das bibliotecas de diferentes unidades orgânicas e, também, bibliotecas temáticas, como é o caso da República Digital, História da Ciência ou Mapas Nabais Conde, que assinalam acontecimentos ou factos importantes diversos e que constituem, no seu conjunto, um repositório bibliográfico de grande valor histórico, bibliográfico e documental. A AlmaMater resultou de um propósito muito claro da Universidade de Coimbra, que foi o de promover e facilitar o acesso aos fundos antigos das suas biblio-

1 Coordenadora do Serviço Integrado das Bibliotecas da Universidade de Coimbra (SIBUC) - evamigueis@sib.uc.pt. Orcid.org/0000-0003-2869-7754 
tecas, aos investigadores e ao grande público, e de os disponibilizar através de uma plataforma na Internet, dando a conhecer o importante património bibliográfico da Universidade e reforçando a sua identidade. Os recursos digitais disponibilizados na AlmaMater abarcam um conjunto diversificado de documentos - livros, jornais, revistas, fotografias, mapas, gravuras - que vão do séc. XIII ao séc. XX, sendo possível percorrer todo este intervalo de tempo de forma ágil e intuitiva.

Neste texto, pretende-se abordar os aspetos mais significativos desta biblioteca digital, fazendo referência à sua estrutura e organização, aos fundos bibliográficos que a constituem, aos aspetos e funcionalidades desenvolvidas e às melhorias implementadas ao longo do tempo.

Reconhece-se que a experiência adquirida no tratamento do património bibliográfico da Universidade de Coimbra, o acompanhamento dos processos de digitalização, o desenvolvimento de plataformas digitais e a integração de objetos digitais foram fatores determinantes para o sucesso deste projeto. Conclui-se afirmando que a AlmaMater é um projeto de grande importância estratégica, com impacto na divulgação do valioso património cultural da Universidade de Coimbra junto de investigadores nacionais e internacionais, e também junto dos cidadãos, cumprindo deste modo com uma importante função universitária, a de suscitar a curiosidade de novos públicos.

\section{PALAVRAS-CHAVE}

Bibliotecas digitais; Universidade de Coimbra; Biblioteca digital de fundo antigo; AlmaMater.

\section{ABSTRACT}

Launched on 30 June 2010, AlmaMater is the digital library of old books of the University of Coimbra, bringing together several digital collections from the General Library, its Faculties libraries and thematic libraries, such as "Digital Republic", "History of Science" or "Nabais Conde Maps", which mark various important events and together establish a bibliographic repository of great historical, bibliographical and documentary value. AlmaMater is the result of the University's very clear purpose to promote and enable greater access to its old books collections to researchers and to the general public, 
and to make them available through an Internet platform becomes known the important bibliographic heritage of the University and reinforcing its identity. The digital resources available at AlmaMater comprise a diverse set of documents - books, journals, newspapers, photographs, maps, manuscripts - dating from the $13^{\text {th }}$ century and extending to the $20^{\text {th }}$.

This paper aims to address the most significant aspects of this digital library, examining its structure and organization, its documental collection, aspects and features developed, and improvements implemented.

The experience achieved in the treatment of the University of Coimbra's bibliographic heritage, the monitoring of digitised procedures, the development of digital platforms, and the integration of digital objects were recognized as determining factors for the accomplishment of this project. It is concluded that AlmaMater is a strategic project of significant worth, with a significant impact on the dissemination of the valuable heritage of the University of Coimbra not only to national and international researchers but also to citizens, therefore fulfilling an important university purpose, to rouse the interest and curiosity of new audiences.

\section{KEYWORDS}

Digital libraries; University of Coimbra; Old books digital libraries; AlmaMater.

\section{Introdução}

Falar de bibliotecas digitais é falar de "bibliotecas", uma vez que as podemos considerar como sendo uma realidade física e virtual de acesso ao conhecimento que cumpre um importante exercício de apoio ao desempenho e à qualidade das instituições académicas. As funções que competem às bibliotecas - como a seleção, o tratamento, a organização e divulgação do conhecimento, aliadas à preservação - assumiram outros contornos com a utilização das novas tecnologias de informação e comunicação que permitem, hoje, um acesso muito mais rápido e fácil à informação, seja sob a forma de catálogos infor- 
matizados, que identificam e descrevem as coleções, seja sob a forma das próprias imagens dessas coleções (MARQUES et al., 2006). As bibliotecas mudaram significativamente nas últimas décadas, período durante o qual surgiu o conceito de "bibliotecas digitais". Assim, para além dos catálogos digitais, foram aparecendo conteúdos digitais em que as bibliotecas de hoje representam um híbrido de uma biblioteca tradicional - com espólios em papel e noutros suportes físicos que importa resguardar e dar à consulta sempre que necessário - e de uma biblioteca moderna, digital e acessível em qualquer local, sem limites espaciais ou de tempo (FIOLHAIS, MARQUES, 2009). Podemos, então, dizer, como Guerreiro (2017) que uma biblioteca digital é uma biblioteca que "[...] disponibiliza em linha obras digitalizadas ou nadas digitais, com um sistema que permite a pesquisa e recuperação da informação. Com os serviços inerentes a uma biblioteca como a organização, gestão da coleção, preservação e disseminação"'2. E podemos distinguir uma biblioteca digital pelo tipo de documento que a constitui, referindo que uma biblioteca digital de Livro Antigo disponibiliza "em formato digital, os incunábulos e o livro antigo"3.

As bibliotecas digitais são, assim, uma realidade incontornável e resultam das possibilidades que o desenvolvimento das novas tecnologias coloca à nossa disposição. Traduzem, muitas vezes, o contexto das bibliotecas físicas e com elas mantêm uma ligação intrínseca e dinâmica. Deste modo, o conceito de Biblioteca Digital é um conceito alargado e plural, que tem evoluído e que procura responder aos desafios que lhe vão sendo colocados ao longo do tempo.

As bibliotecas digitais são também um objetivo da International Federation of Library Associations and Institutions (IFLA), que viu reco-

2 GUERREIRO, Dália Maria Godinho - Bibliotecas digitais para as Humanidades: novos desafios e oportunidades [Em linha]. Évora: [do autor], 2017. Tese de doutoramento. [Consult. 28 set. 2019]. Disponível na Internet em: <http://hdl.handle. net/10174/23282>. p. 1.

3 GUERREIRO - Bibliotecas digitais para as Humanidades... p. 1. 
nhecido pela UNESCO o seu "Manifesto para as Bibliotecas Digitais", na Conferência Geral de novembro de 2011. Neste Manifesto, a IFLA e a UNESCO encorajam os governos e as organizações internacionais a desenvolver estratégias de digitalização e a criar bibliotecas digitais como forma de facilitar o livre acesso à informação, designadamente a conteúdos digitais, contribuindo assim para a preservação do património cultural e científico.

A Universidade de Coimbra (UC) reuniu ao longo da sua história um riquíssimo espólio bibliográfico e documental que importa preservar e dar conhecer. A Biblioteca Geral (BGUC) guarda muitos desses tesouros que garantem a memória e a identidade da instituição na sua dimensão cultural e civilizacional. Uma das suas atribuições é, naturalmente, "a preservação, o enriquecimento, o tratamento técnico e a difusão do seu património bibliográfico e documental" ${ }^{\prime \prime}$, cabendo-Ihe também a produção de conteúdos digitais. Em colaboração com o Serviço Integrado das Bibliotecas da Universidade de Coimbra (SIBUC), e com as outras bibliotecas da Universidade, a digitalização de fundos patrimoniais e sua disponibilização tornou-se uma realidade. É ao SIBUC que compete gerir a biblioteca digital da UC, em ligação próxima com o Serviço de Gestão de Sistemas e Infraestruturas de Informação e Comunicação da Universidade (GSIIC) e com a BGUC, assim como o desenvolvimento de novas versões e funcionalidades do sistema que suporta a biblioteca digital. É também o SIBUC que apoia e promove a coordenação de ações de digitalização de obras e documentos das restantes bibliotecas e, nesta convergência de ação e de propósitos, a UC conseguiu acompanhar de modo consistente e

4 Veja mais informação sobre o Manifesto para as Bibliotecas Digitais na página Web da IFLA. [Consult. 14. Outubro, 2019]. Disponível na Internet em: <https://www.ifla.org/ files/assets/digital-libraries/documents/ifla-unesco-digital-libraries-manifesto.pdf>.

5 In Regulamento da Biblioteca Geral, publicado em Diário da República a 10 de dezembro de 2009. 
coordenado a evolução determinada pelos desenvolvimentos informáticos mais recentes.

Por outro lado, a UC tem sido produtora e fornecedora de informação e de conhecimento através das publicações editadas, quer pela Imprensa da Universidade (IUC) ou com a sua chancela, quer ainda pelas dissertações de mestrado e teses de doutoramento, artigos com arbitragem publicados em revistas internacionais ou nacionais e outras publicações, que têm vindo a ser colocadas na Internet (com a salvaguarda dos direitos de autor) de forma estruturada e organizada, quer no Estudo Geral (repositório digital da Universidade de Coimbra), quer na UC Digitalis (plataforma criada pela UC para a divulgação e promoção de conteúdos digitais em língua portuguesa).

Neste texto, a nossa abordagem centra-se na AlmaMater, biblioteca digital que contém obras digitalizadas não apenas de Fundo Antigo, mas também obras mais recentes, em geral publicadas antes de 1940. A disponibilização na Internet de acervos bibliográficos digitalizados, em particular acervos de fundo antigo, representa um importante contributo para a investigação, ao facilitar o acesso à informação e ao conhecimento. No entanto, a preocupação em disponibilizar esses conteúdos de modo a facilitar e a garantir a sua utilização por parte dos investigadores (nomeadamente na identificação, localização, navegação e pesquisa das obras) deve ser uma constante no desenvolvimento das soluções técnicas a aplicar. Atualmente, já se solicita às bibliotecas digitais que forneçam serviços personalizados, que integrem ferramentas úteis a grupos específicos de utilizadores, como os investigadores, e recomenda-se que, para potenciar a sua utilização, se criem e desenvolvam páginas de ajuda, se realize formação e se divulgue por novos meios estas bibliotecas (GUERREIRO, BORBINHA, 2014). Ajustar ou flexibilizar as soluções técnicas que lhe dão suporte é uma caraterística própria das bibliotecas digitais, que assim procuram responder aos desafios constantes que se lhe colocam para permitir uma utilização mais 
fácil dos recursos digitais, tornando-os mais intuitivos e acessíveis (GUERREIRO, BORBINHA, 2014).

\section{A Criação da biblioteca digital Almamater}

Em Portugal, a partir dos inícios do século XXI e à semelhança do que aconteceu em muitos outros países, foram criados repositórios digitais com imagens integrais de fontes históricas, mas que, na sua maioria, tiveram dificuldade em se manter após o termo dos projetos que lhe deram origem ${ }^{6}$.

Há, no entanto, que destacar neste panorama a Biblioteca Nacional Digital (BND), criada em 2002 como um projeto da Biblioteca Nacional de Portugal (BNP), que disponibiliza em linha e de forma gratuita cerca de 25000 documentos digitais constituídos por livros, publicações periódicas, iconografia, cartografia e música e que soma mais de 7 milhões de visitas por ano7. A BND está hoje completamente integrada na infraestrutura geral de serviços da BN e pode dizer-se que a sua intervenção assenta nos princípios da responsabilidade patrimonial e da democratização do acesso e que se estrutura em função de quatro componentes principais: i) disponibilização dos conteúdos (mais) procurados pela comunidade de leitores de uma biblioteca nacional, privilegiando-se as fontes documentais; ii) formação de um acervo coerente que traduz a identidade da BNP e das suas coleções mais significativas; iii) cumprimento de funções de extensão cultural para a difusão e valorização dos seus fundos documentais; iv) articu-

6 Veja-se, a este propósito, o caso do "Fundo Antigo da Faculdade de Ciências da Universidade do Porto", cujo Projecto de Informatização, Digitalização e Divulgação do Fundo Bibliográfico Antigo decorreu de 2005 a 2007 e não teve continuidade. [Consult. 13. Outubro, 2019]. Disponível na WWW em: < https://www.fc.up. $\mathrm{pt} / \mathrm{fa} / \mathrm{p} \mathrm{p}=$ apr\&item $=363 \# \mathrm{mis}>$.

7 Informação em "Sobre a BND. Apresentação". [Consult. 13. Outubro, 2019]. Disponível na WWW em: http://purl.pt/index/geral/PT/about.html>. 
lação com uma funcionalidade designada como "Biblioteca Nacional a distância" (REIS, 2015).

Entre os motivos que contribuíram para o aparecimento de uma biblioteca digital de fundo antigo na UC salienta-se a importância da Biblioteca Geral da Universidade de Coimbra, biblioteca de cariz patrimonial e detentora de depósito legal, com o propósito de defender e preservar os valores da língua e cultura portuguesas. A proximidade ao Arquivo da Universidade de Coimbra (AUC), depositário da documentação produzida e recebida pela Universidade de Coimbra desde a data da sua fundação (uma função que acumula com a de arquivo distrital), contribuiu para essa decisão. Também o AUC tem a missão de coordenar a produção de conteúdos digitais do acervo arquivístico e do seu plano de trabalho faz parte a digitalização para divulgar e preservar o conhecimento. Acresce-se ainda um outro motivo, o da classificação da Universidade de Coimbra como Património Mundial pela UNESCO, em junho de 2013, galardão que inclui não apenas a Biblioteca Joanina, mas também todas as outras bibliotecas universitárias de Coimbra, o que veio enfatizar o lugar da instituição no espaço da cultura e da língua portuguesas. Esta circunstância obrigou a uma atenção renovada aos recursos bibliográficos de que a Universidade de Coimbra é depositária e ao modo como os preserva e disponibiliza.

Partindo destes pressupostos, e estimulada pela concretização dos primeiros projetos de digitalização que apoiavam financeiramente a criação de uma biblioteca digital, a UC apresentou publicamente, em julho de 2010, a AlmaMater, nome que designa a sua biblioteca digital de fundo antigo. Desde esta data e até hoje a AlmaMater tem sido um importante repositório de fundo antigo em suporte digital, sendo o maior das universidades portuguesas e o segundo do país, depois do repositório da BND. A AlmaMater reuniu desde o seu início documentos do acervo da BGUC e também fundos antigos das Bibliotecas da Faculdade de Direito, da Faculdade de Letras e do antigo Departa- 
mento de Botânica (esta última integrada hoje no Departamento de Ciências da Vida da Faculdade de Ciências e Tecnologia da UC).

Os primeiros projetos lançados pela BGUC (2005) e mais tarde pelo SIBUC (2007), os quais antecederam o lançamento da AlmaMater, foram suportados pelo Programa Operacional da Cultura (POC) do Ministério da Cultura (2007), como foi o caso da Biblioteca Geral Digital e das Bibliotecas Digitais da Faculdade de Direito e da Faculdade de Letras, e ainda pelo Programa Operacional da Sociedade do Conhecimento, como aconteceu com a Biblioteca Digital da Botânica (2008). Outros projetos autónomos vieram aumentar substancialmente a AlmaMater após a sua criação, como aconteceu com o "Instituto de Coimbra" e a "História da Ciência na UC", ambos apoiados pela Fundação para a Ciência e a Tecnologia (MIGUÉIS, FIOLHAIS, 2014); ou ainda com os projetos integrados em comemorações, como o da "República Digital" no centenário da República (2010) e o dos "500 Anos, 500 Obras", a assinalar os 500 anos da Biblioteca da UC no ano de 2013. Mais recentemente foram apresentadas as bibliotecas "Rómulo Digital" (2018), com financiamento do Ministério da Ciência e Tecnologia, e a Biblioteca "Mapas Nabais Conde" (2019), que reúne a maior coleção privada portuguesa de mapas antigos com representação do território de Portugal, reunida pelo Professor Carlos Alberto Nabais Conde, da Universidade de Coimbra, a qual foi adquirida pela BGUC em 2011 e que merece um artigo autónomo (da autoria conjunta de Maria de Fátima Moura de Carvalho e Teresa Margarida Simões Mendes) neste mesmo volume.

Na organização e apresentação dos documentos que constituem a AlmaMater houve sempre a necessidade de respeitar algumas diretrizes que estiveram na origem desta biblioteca digital, como seja a de manter a localização de origem. Isto significa que cada biblioteca física que deu origem a um projeto de digitalização, ou que tem documentos do seu acervo digitalizados, conserva a sua identidade e individualidade, ainda que, no seu conjunto, todas as bibliotecas 
obedeçam a uma lógica comum e estejam integradas numa mesma estrutura. $\mathrm{O}$ trabalho de digitalização foi, na grande maioria das situações, adquirido a empresas externas, mas a coordenação técnica foi assegurada pelo SIBUC.

O conjunto de documentos digitalizados foi crescendo, mercê dos apoios recebidos pela Reitora da UC e dos projetos financiados, e a sua disponibilização ao público foi suportada pelo trabalho desenvolvido pelo SIBUC. Em março de 2013, a AlmaMater alcançou perto de 6000 mil documentos, a que correspondiam mais de um milhão de imagens (FIOLHAIS et al., 2013).

O trabalho inicial de seleção e triagem dos documentos a digitalizar esteve a cargo de bibliotecários, responsáveis pelo levantamento dos documentos considerados mais relevantes na sua Biblioteca e de acordo com critérios estabelecidos: o interesse manifestado pelos investigadores na sua consulta, o estado de conservação e a raridade ou número de exemplares existentes. Após uma recolha inicial, foi necessário confirmar se, na Internet, já existia alguma cópia desse documento, ou de um similar. Existindo, esse documento, tendencialmente, passava para a base da lista e dava-se prioridade a outro que ainda não estivesse digitalizado e acessível na Internet. Adotado este método de trabalho, foi então possível selecionar um conjunto considerável de obras e dar início ao trabalho de digitalização, complementado com a criação de registos bibliográficos e com a catalogação de muitos documentos que ainda não se encontravam inseridos no catálogo do sistema integrado de informação bibliográfica de todas as Bibliotecas da UC.

\section{Fundo documental e breve caraterização}

Já antes se mencionaram alguns dos projetos que permitiram a digitalização e disponibilização de importantes fundos bibliográficos 
à guarda das Bibliotecas da UC e que deram corpo à AlmaMater. Referir-nos-emos com um pouco mais de detalhe a alguns deles, procurando seguir uma ordem cronológica na sua apresentação.

Os primeiros projetos, que visavam a conservação do património bibliográfico apoiados pelo POC, foram a "Biblioteca Joanina Virtual", a "Biblioteca Geral Digital" e a "Biblioteca Digital da Universidade de Coimbra". Os dois primeiros iniciaram-se em 2005, sob a responsabilidade da Biblioteca Geral, procurando, o primeiro, reconstituir tridimensionalmente todo o espaço da Biblioteca Joanina e permitir a visita virtual à Biblioteca Joanina e ao seu excecional património documental, produzindo para esse efeito um sítio Web e um DVD, ambos lançados em 2008 (AMARAL, 2014); o segundo projeto visava digitalizar um conjunto significativo de obras antigas, para além do notável catálogo de miscelâneas e manuscritos da Biblioteca Geral (FIOLHAIS, MARQUES, 2009). Neste último, o objetivo passava pela digitalização, tratamento técnico e colocação na Internet de perto de 60000 imagens, perfazendo o total de cerca de 600 obras (FIOLHAIS, 2008). As obras escolhidas, no conjunto dos dois projetos da Biblioteca Geral, citando Carlos Fiolhais (2008), foram:

"[...] os incunábulos que não existiam em mais nenhuma biblioteca portuguesa (123 obras), toda a tipografia coimbrã do século XVI (108 obras) e parte da do século XVII (24 obras), impressos musicais (50 obras), alguns álbuns de Piranesi, todos os códices iluminados, as plantas pombalinas e a maioria dos manuscritos científicos, alguns literários e alguns musicais. Entre as publicações periódicas, sobretudo jornais antigos de Coimbra, estão 47 títulos completos. Exemplos de documentos digitalizados são várias bíblias latinas do século XIII manuscritas, a Bíblia de Abravanel (bíblia hebraica do século XV), a "Nova Astronomia..." de Cristóvão Borri, a "Discrittione et historia de I' Isole Canarie..." (um manuscrito ilustrado) de Leonardo Torriani, a "Carta portulano" de Diogo Homem (carta do século XVI) e ainda algumas primeiras edições que são marcos da cultura portuguesa: a "Peregrinação" 
(1614), o "Só" (1892), a "Mensagem" (1934), etc. A estes recursos digitais acrescem outros, que tinham sido produzidos antes (como a edição original de "Os Lusíadas") e que foram unidas num quadro comum." ${ }^{8}$

Também as Bibliotecas das Faculdades de Direito e de Letras e do Departamento de Botânica da Faculdade de Ciências e Tecnologia iniciaram a digitalização de importantes núcleos documentais à sua guarda9. A Biblioteca Digital da Faculdade de Direito de Coimbra (2007) dispõe de uma coleção de Livro Antigo constituída, na sua maioria, por obras recebidas da livraria do antigo Colégio de São Pedro, de autores portugueses formados na Universidade de Coimbra e estreitamente ligados às antigas Faculdades de Leis e Cânones. Também tem obras de autores que se formaram no estrangeiro, mas que foram atraídos pelo renome alcançado pela UC, como Manuel da Costa e Aires Pinhel. Na Biblioteca Digital da Faculdade de Letras (2008) existem obras significativas, como os manuscritos de Almeida Garrett, o manuscrito sobre as regras das freiras do Mosteiro de Santa Clara, entretanto publicado por Maria José Azevedo Santos ${ }^{10}$, cartas autografadas de Honoré de Balzac e, ainda, obras com desdobráveis de projetos de fortificações, como a de Luís Serrão Pimentel no "Método lusitano de desenhar as fortificações das praças regulares e irregulares...". Já da Biblioteca Digital de Botânica (2008), pertença do antigo Departamento de Botânica, digitalizou-se um conjunto de livros antigos, manuscritos e uma parte importante dos espólios dos

8 FIOLHAIS, Carlos - A Biblioteca digital da Universidade de Coimbra. Rua Larga. N.o 19 (2008), p. 20.

9 Relativamente a este ponto, muita da informação introduzida foi retirada da página Web da Biblioteca Digital da Faculdade de Direito, disponível em https://bibdigital.fd.uc.pt/website/apresentacao.htm, assim como da página Web do Serviço Integrado das Bibliotecas da Universidade de Coimbra, área de apresentação e fundo documental da biblioteca digital do fundo antigo Alma Mater, disponível em: <https://www.uc.pt/sibuc/Alma Mater/fundodocumental>.

10 SANTOS, Maria José Azevedo - As regras da Regra de Santa Clara. Códice do século XVI. Coimbra: Imprensa da Universidade de Coimbra, 2015. 
botânicos Avelar Brotero, Júlio Henriques e Luís Carrisso, entre outros, composto por correspondência manuscrita, fotografias e desenhos.

Para dar suporte ao trabalho já realizado, a Reitoria criou, ainda em 2008, um novo projeto de digitalização, o da "Biblioteca Digital da Universidade de Coimbra", que pretendia reunir obras da Biblioteca Geral e das Bibliotecas das Faculdades de Direito, Letras e Ciências e Tecnologia (Botânica), entretanto digitalizadas e alargar o âmbito do projeto às restantes bibliotecas para prosseguir o trabalho anterior e aumentar a visibilidade da Universidade na Internet (FIOLHAIS, 2008; FIOLHAIS, MARQUES, 2009). Este projeto foi, desde o seu início, gerido pelo SIBUC.

Outros projetos importantes que importa referir são:

O relativo ao "Instituto de Coimbra", academia coimbrã que desempenhou um papel de relevo para a Universidade ao afirmar-se como uma instituição que proporcionou grande incentivo ao ensino e à investigação. Este projeto decorreu entre 2008 e 2014 e consistiu no tratamento documental da biblioteca e arquivo, assim como na investigação da história da academia, tendo sido financiado pela Fundação para a Ciência e a Tecnologia (FCT). Este espólio ingressou na Biblioteca Geral num estado de grande desorganização, com documentos em falta e degradados fisicamente, o que dificultou o conhecimento da ordem original pela qual foram produzidos. A digitalização, na íntegra, da revista científico-cultural "O Instituto" representou um importante desafio, uma vez que se tratava de uma publicação com mais de 100 anos de existência, com uma cobertura abrangente de diversas áreas do conhecimento e que deu "[...] expressão à sua finalidade de cultivar quer as ciências, quer as letras, quer as artes"11. Foi publicada em Coimbra entre 1851 e 1981, tendo alcançado grande prestígio e longevidade (FERREIRA, 2012).

11 FERREIRA, Licínia Rodrigues - Instituto de Coimbra: o percurso de uma academia. p. 218. 
Um outro projeto que se seguiu foi o da "República Digital" (2010), sob o patrocínio da Comissão das Comemorações do Centenário da República da Universidade de Coimbra, com a digitalização de muitos documentos da época da Primeira República, incluindo documentos inéditos ou pouco conhecidos de correspondência, fotografias, jornais, manifestos, revistas científicas e trabalhos universitários, representativos das transformações políticas, sociais, científicas e artísticas em Portugal durante este período, de modo particular na cidade de Coimbra, como é ilustrado pelas "Memórias" e as fotografias do Coronel Belisário Pimenta, o fundo de Armando Cortesão ou os periódicos "Gazeta de Coimbra", "Ultimato", "Resistência" e "Revolta". Em muitos destes jornais recorreu-se a parte das coleções da Biblioteca Municipal de Coimbra para completar as da Biblioteca Geral.

O projeto "História da Ciência" inseriu-se num programa mais vasto, intitulado "História da Ciência na Universidade de Coimbra (1547 -1933): da construção do Colégio de Jesus ao Estado Novo", e teve financiamento da FCT, o que permitiu a digitalização de bibliografia, fontes documentais, objetos e instrumentos científicos, incluindo de modo equilibrado as várias disciplinas do saber e trazendo à AlmaMater um número considerável de documentos sobre a história da ciência portuguesa, nomeadamente os relacionados com a atividade científica da UC. O levantamento de documentos relevantes para este projeto foi realizado não apenas na BGUC, mas em todas as bibliotecas das faculdades e departamentos e conduziu à digitalização, durante o ano de 2011, de cerca de 120000 imagens de documentos sobre história da ciência, com o objetivo de dar suporte a novas investigações (FIOLHAIS et alii, 2013).

Mais recentemente, foram criadas outras coleções digitais, como a coleção "500 Anos|500 Obras", em 2014, projeto esse que integrou a comemoração dos 500 anos de existência da biblioteca da UC. Nesta biblioteca incluem-se não só obras significativas da Biblioteca Geral, 
mas também publicações emblemáticas de outras bibliotecas da Universidade de Coimbra.

A biblioteca "Rómulo Digital" consistiu na digitalização de fundos pertencentes ao RÓMULO - Centro Ciência Viva da UC, provenientes da biblioteca do antigo Museu Nacional da Ciência e da Técnica. Este projeto, realizado em 2018-2019 com o apoio do Ministério da Ciência e Tecnologia, disponibiliza obras que documentam a história da ciência e da tecnologia em Portugal, desde finais do século XVIII a meados do século $X X$, em particular as que ilustram invenções e inovações científico-técnicas no seio da sociedade portuguesa.

A coleção "Mapas Nabais Conde" (2019) dá a conhecer o espólio de mapas antigos adquirido em 2011 pela Biblioteca Geral ao Professor Carlos Nabais Conde, que reuniu uma importante e completa coleção privada portuguesa de mapas antigos com representação do território de Portugal, onde se incluem centenas de mapas impressos e manuscritos que mostram a representação cartográfica do nosso país. Nesta coleção encontra-se um exemplar do primeiro mapa impresso de Portugal, da autoria de Álvares Seco (datado de 1560), com edições de Tramezini, De Jode, Ortelius e Blaeu, entre tantos outros, para além de imagens e gravuras de cidades de Munster, imagens de Coimbra no século XVI, de Lisboa no século XVIII, pouco antes do Terramoto, e cartas náuticas de vários trechos da costa portuguesa.

\section{A evolução da AlmaMater}

A aspiração dos primeiros projetos delineou, desde o início, o essencial do que se pretendia que fosse a futura biblioteca digital da UC e que consistia não somente na digitalização, tratamento técnico e disponibilização de imagens de obras do importante espólio da Biblioteca Geral e das restantes bibliotecas da UC com vista a criar uma biblioteca digital, mas, sobretudo, a de produzir conhecimento 
na área, criando os procedimentos necessários ao desenvolvimento de uma biblioteca virtual (FIOLHAIS, 2008). Nesse sentido, foi adquirido equipamento para a preservação digital, constituído por servidores e discos que asseguram uma adequada manutenção das imagens digitalizadas e das bases de dados que armazenam a informação necessária à sua descrição. A realização de ações de formação para os técnicos superiores e outros funcionários, pertencentes às equipas dos projetos nas bibliotecas envolvidas, também foi uma realidade.

Com o esforço coletivo das várias bibliotecas da UC, mediante a estreita cooperação entre os bibliotecários envolvidos, foi possível economizar recursos e apresentar resultados padronizados, o que permitiu encetar outros projetos que conduziram à criação da biblioteca digital da Universidade de Coimbra, batizada com o nome de AlmaMater. Foi ao SIBUC, criado em 2007'12, que coube coordenar este ambicioso projeto de preservação e divulgação do património bibliográfico e documental da UC, mediante uma conveniente digitalização e/ou restauro, trabalho feito com a participação estreita da Biblioteca Geral e em cooperação com a Biblioteca Nacional (FIOLHAIS, MARQUES, 2009).

A parte mais inovadora do projeto consistiu na criação de uma aplicação informática, bem articulada com o sistema do catálogo das bibliotecas da UC, que permitia a pesquisa dos Catálogos de Manuscritos e de Miscelâneas da Biblioteca Geral tendo, para tal, submetido os catálogos impressos a um processo de reconhecimento ótico de caracteres, enriquecido pelas operações de etiquetagem manual de autores, títulos, datas, locais, etc. e sua indexação automática (FIOLHAIS, 2008). Através destas operações pesquisava-se não só por

12 O SIBUC começou a funcionar em 2007, sob a direção do Prof. Doutor Carlos Fiolhais e coordenação técnica da Dr. ${ }^{a}$ Leonor Marinho Dias, que aí se manteve até fevereiro de 2010. O conjunto de normas de organização e funcionamento do SIBUC apenas foram publicado em Diário da República a 10 de dezembro de 2009, sob o Regulamento n. ${ }^{\circ} 488 / 2009$. 
palavras-chave, mas também no texto digitalizado dos catálogos. Esta mesma tecnologia já tinha sido aplicada à edição digital da revista "O Instituto" disponibilizada na Web e com acesso à coleção completa através da pesquisa em texto integral por autor, título e palavra significativa e com a possibilidade de fazer o download dos artigos ${ }^{13}$.

Os primeiros projetos adotaram normas e procedimentos usados pela Biblioteca Nacional de Portugal e a colaboração institucional entre as duas instituições foi condição importante para a complementaridade de fundos bibliográficos, não repetindo obras já digitalizadas. Na plataforma criada para alojar e apresentar os conteúdos digitalizados, adotou-se o esquema METS (Metadata Encoding and Transmission Standard), usado pela BNP para a codificação dos objetos digitais, incluindo também os metadados bibliográficos. Usaram-se os programas PAPAIA e ContentE, desenvolvidos pela BNP, para a utilização de uma infraestrutura que recorresse ao uso de soluções informáticas abertas, normalizadas, escaláveis, reutilizáveis e sustentáveis a longo prazo ${ }^{14}$.

Foi já em 2013 que a AlmaMater foi inserida numa nova plataforma, a UC Digitalis, um projeto mais abrangente e estratégico da Universidade para a agregação e difusão de conteúdos digitais de cultura e ciência produzidos em espaço lusófono. A UC Digitalis, apresentada ao público em 2012, já reunia duas bibliotecas digitais da Imprensa da Universidade de Coimbra (IUC): a Impactum e a Pombalina, que incluem, respetivamente, publicações periódicas e monografias maioritariamente publicadas com a chancela da IUC. A integração da AlmaMater na UC Digitalis resultou igualmente do facto de o SIBUC

13 Informação retirada da página do blog RCAAP, de uma notícia publicada em 2010, aquando da apresentação pública da edição digital da revista "O Instituto", consultada a 17 de novembro de 2019. Disponível na Internet em: <https://blog. rcaap.pt/2010/01/18/instituto-de-coimbra>

14 Informação retirada da antiga página Web da Biblioteca Digital de Botânica, consultada a 16 de novembro de 2019. Disponível na Internet em: <URL: http://bibdigital. bot.uc.pt/index.php?menu=10\&language $=$ pt $\&$ tabela $=$ geral $>$. 
ter tido um papel preponderante na criação e desenvolvimento desta plataforma, fruto de experiências anteriores, nomeadamente de projetos como o repositório digital da UC, o Estudo Geral, a biblioteca digital Classica Digitalia e o portal dos Serviços de Biblioteca e Documentação da Faculdade de Letras da Universidade de Coimbra (SBDFLUC).

O modelo informático adotado na conceção da UC Digitalis assentou na identificação dos principais requisitos necessários ao seu bom funcionamento, como a acessibilidade da plataforma através da Web, a agregação de recursos, a capacidade de pesquisa (um dos seus atributos essenciais), a existência de uma área pessoal de utilizador e a possibilidade de criar listas de referências bibliográficas. O uso de sistemas de gestão de conteúdos open source para o desenvolvimento da plataforma foi também uma condição estabelecida $a$ priori (MIGUÉIS et alii., 2014) e a solução adotada consistiu na utilização de dois sistemas de gestão de conteúdos complementares: um para gestão e administração dos objetos digitais e outro onde são expostos os conteúdos e onde o utilizador acede. $\mathrm{O}$ armazenamento dos objetos digitais - texto integral e subprodutos - foi feito no sofware DSpace e o software Drupal foi usado devido às vantagens da sua capacidade de inclusão e desenvolvimento de novas funcionalidades. Também foi adotado o esquema qualificado de metadados Dublin Core, devido à sua capacidade de interoperabilidade, que expõe os metadados da AlmaMater através do protocolo OAI-PMH e que permite a respetiva agregação por diferentes tipos de conteúdos, em função da tipologia de documento, com conjuntos de informação e filtros modificadores. Foi possível, por esta via, realizar um conjunto de funcionalidades na "nova" biblioteca AlmaMater que permitiram ao utilizador não apenas "navegar" pelos índices dos documentos digitalizados, como até aí, mas também realizar uma pesquisa fácil em todos os seus recursos. 
No entanto, vários dos desenvolvimentos que se pretendiam implementar não foram concretizados e a solução ficou incompleta e aquém do que se pretendia. Foi apenas em 2018 que se conseguiu prosseguir para uma nova fase de desenvolvimento, quando surgiu a oportunidade de desenvolver um novo projeto, o "Rómulo Digital", que consistiu na criação de uma nova biblioteca digital, inserida na AlmaMater. O financiamento de que o projeto foi alvo permitiu adotar uma solução mais moderna e completa, com o objetivo de proporcionar o acesso a parte do espólio mais antigo do Rómulo através de um serviço público com uma interface adequada, independente de dispositivos particulares, prestando serviços biblioteconómicos avançados e implementando um sistema que contribua para a qualificação dos cidadãos (MIGUÉIS, FIOLHAIS, no prelo). Este projeto foi desenvolvido pelo SIBUC, em estreita articulação com o centro RÓMULO - Ciência Viva, e contou com a colaboração da Biblioteca Geral, da Biblioteca da Faculdade de Letras e da Biblioteca de Física e Química da Faculdade de Ciências e Tecnologia, de modo a possibilitar um acesso coerente a coleções e autores, quer para utilizadores locais, quer para os que se encontram geograficamente afastados. As tarefas associadas à configuração da plataforma de gestão de bibliotecas digitais para receber os conteúdos da Rómulo Digital e permitir a sua plena integração na AlmaMater, assim como a conceção e criação de uma interface gráfica adequada aos objetivos propostos, foram determinantes para o sucesso deste projeto (MIGUÉIS, FIOLHAIS, no prelo).

Atualmente, a disponibilização dos conteúdos antigos da AlmaMater é realizada numa plataforma da UC gerida pelo SIBUC e preparada para alojar qualquer tipo de conteúdos digitais. Sobre este sistema, têm sido efetuados desenvolvimentos com vista a simplificar a interface de utilização e a torná-la mais acessível a públicos generalistas. A opção pela utilização desta plataforma permitiu maximizar o investimento na digitalização de conteúdos, diminuir o tempo para entrada em produção e, acima de tudo, garantir a sustentabilidade do projeto. 
Neste contexto, para além dos objetivos enunciados, pretendeu-se dar resposta a questões como a de simplificar a disponibilização de bibliotecas digitais, mantendo a identidade específica de cada uma; ter interfaces de uso independentes do dispositivo de utilização; ter um sistema de armazenamento e de preservação com capacidade para gerir qualquer tipo de conteúdos digitais; integrar as APIs IIIF (International Image Interoperability Framework) para a visualização de imagens de alta qualidade com funcionalidade de deep zooming; disponibilizar os conteúdos e metadados digitais através de uma solução que permita disseminar e reutilizar estas componentes do património cultural da UC; e permitir a migração de conteúdos e metadados de bibliotecas digitais existentes (SILVA et alii., 2019).

$\mathrm{Na}$ aplicação que foi desenvolvida, existem duas áreas distintas de intervenção, sendo uma a área pública e a outra a área reservada à gestão da biblioteca digital. Na área pública - com o endereço https:// am.uc.pt - os utilizadores podem realizar uma pesquisa global com a possibilidade de filtrar os resultados por facetas ou através da linha de tempo, aceder às imagens dos documentos - através de um visualizador que oferece uma excelente qualidade de imagem e a possibilidade de atingir um pormenor com grande nitidez através do deep zooming do IIIF; é-lhes, também, apresentada uma sugestão de itens relacionados com o que estão a ver e a possibilidade de transferir conteúdos, entre outras funcionalidades. Dentro da área de gestão, para além da criação de novas bibliotecas digitais, é possível adicionar elementos que definam a sua identidade gráfica, editar texto ou acrescentar páginas com informação mais detalhada. O modelo de armazenamento que foi implementado é bastante flexível e permite associar cada item a uma ou mais bibliotecas digitais da AlmaMater sem que exista qualquer prejuízo para a identidade gráfica de cada biblioteca, princípio que tem sido respeitado desde os primeiros projetos de digitalização. 


\section{Conclusão}

O propósito de dar a conhecer o rico espólio bibliográfico documental da mais antiga universidade do país através do repositório digital AlmaMater, de forma universal e sem restrições ao acesso, contribuiu para que se alcançasse maior visibilidade e conhecimento destes fundos documentais. Por outro lado, a vasta experiência acumulada pelos sucessivos projetos de criação de bibliotecas digitais, que decorreram ao longo da última década, permitiram ao SIBUC assegurar uma evolução coerente e sólida da infraestrutura adotada, recorrendo a soluções mais modernas e ágeis sempre que houve ocasião para o fazer, sem que os princípios que nortearam os primeiros projetos fossem colocados em causa.

Os últimos projetos em que se tem vindo a trabalhar permitiram desenvolver e implementar uma solução baseada em sistemas e protocolos abertos para suporte e apresentação da AlmaMater e ampliar o conjunto de coleções digitais, recorrendo a um ponto único de armazenamento e de gestão, o que constitui um recurso fundamental para a preservação do património digital da Universidade de Coimbra e do país.

Dar a conhecer a Universidade de Coimbra como uma instituição multissecular e valorizá-la como um espaço de transmissão de cultura, investigação e conhecimento é o objetivo final da biblioteca digital AlmaMater, ao disseminar e possibilitar o uso e a recuperação da informação associada aos recursos digitais disponibilizados aos investigadores nacionais e internacionais e ao público em geral. E, deste modo, a Biblioteca continua a cumprir a sua missão de sempre: preservar e divulgar o conhecimento humano. 


\section{Referências bibliográficas}

AMARAL, A. E. Maia do - Os livros em sua ordem: para a história da Biblioteca Geral da Universidade (antes de 1513-2013). Coimbra: Imprensa da Universidade de Coimbra, 2014. ISBN 978-989-26-0893-8.

FIOLHAIS, Carlos - A Biblioteca Digital da Universidade de Coimbra. Rua Larga. ISSN 1645-765X. 19 (2008) 18-20.

FIOLHAIS, Carlos; MARQUES, João Carlos - A BGUC e as bibliotecas da Universidade de Coimbra. In Tesouros da Biblioteca Geral da Universidade de Coimbra. Coimbra: Imprensa da Universidade de Coimbra, 2009. ISBN 978-989-26-0015-4. pp. 133-139.

FIOLHAIS, Carlos; MARTINS, Décio; MIGUÉIS, Ana; PEREIRA, Paula; Silva, Ana Luísa AlmaMater, o repositório digital de fundo antigo da Universidade de Coimbra [Em linha]. In FIOLHAIS, Carlos; SIMÕES, Carlota; MARTINS, Décio, ed. - História da ciência luso-brasileira: Coimbra entre Portugal e o Brasil. Coimbra : Imprensa da Universidade de Coimbra, 2013. ISBN 978-989-26-0562-3. pp. 295-301. [Consult. 10 out. 2019]. Disponível na Internet em: <http://hdl.handle.net/10316/32052>.

GUERREIRO, Dália; BORBINHA, José Luís - Humanidades Digitais: novos desafios e oportunidades [Em linha]. Cadernos BAD [Em linha]. ISSN 0007-9421. 1 (2014) 63-78. [Consult. 28 set. 2019]. Disponível na Internet em:<https://www.bad.pt/publicacoes/ index.php/cadernos/article/view/1060/pdf>.

GUERREIRO, Dália Maria Godinho - Bibliotecas digitais para as Humanidades: novos desafios e oportunidades [Em linha]. Évora: [ed. do autor], 2017. Tese de doutoramento. [Consult. 28 set. 2019]. Disponível na Internet em:< http://hdl.handle. net/10174/23282>.

FERREIRA, Licínia Rodrigues - Instituto de Coimbra: o percurso de uma academia [em linha]. Coimbra: [s.n.], 2012. [Consult. 30 out. 2019]. Disponível na Internet em:<http:// hdl.handle.net/10316/21257.

MARQUES, João Carlos, et al., coord. - Reorganização e reestruturação das bibliotecas da Universidade de Coimbra : relatório. Coimbra: Universidade de Coimbra, 2006.

MIGUÉIS, Ana - ALMAMATER: acesso e preservação numa biblioteca de fundo antigo [Em linha]. In PEREIRA, Ana Alves [et alii], coord. - Encontro Curadoria Digital - Estratégias e experiências: atas. [Em linha]. Lisboa: Instituto de História Contemporânea da FCSH-UNL. ISBN 978-972-96844-9-4. pp. 57-61. Disponível na Internet: <http://hdl. handle.net/10316/43314>.

MIGUÉIS, Ana Eva; FIOLHAIS, Carlos - RÓMULO DIGITAL: digitalização de fundos de cultura científica da Universidade de Coimbra. In BORGES, M. M. e SANZ-CASADO, E., eds - A Ciência Aberta: olhares de Portugal, Espanha e Brasil. Coimbra: Imprensa da Universidade. [no prelo].

MIGUÉIS, Ana; FIOLHAIS, Carlos - Recursos digitais em livre acesso na Universidade de Coimbra: Estudo Geral e AlmaMater [Em linha]. RECIIS. eISSN 1981-6278. 8 : 2 (2014) 
231-242. [Consult. 30 set. 2019] Disponível na Internet em: <https://www.reciis.icict. fiocruz.br/index.php/reciis/article/view/635>.

MIGUÉIS, Ana; SILVA, Ana Luísa; TRINDADE, Álvaro; NEVES, Bruno - Sistemas abertos aplicados à gestão da informação científica: o desenvolvimento da UC Digitalis [Em linha]. Cadernos BAD. ISSN 0007-9421. 2 (2014) 183-188. Disponível na Internet em: <http://hdl.handle.net/ 10316/ 28200>.

REGULAMENTO N.o 487/2009. Regulamento da Biblioteca Geral da Universidade de Coimbra. D.R. Il Série. 238 (2009-12-10) 49899-49902.

REIS, Carlos - As bibliotecas digitais ou a Noruega no século XXVII. In A Biblioteca da Universidade: permanência e metamorfoses. Coimbra: Imprensa da Universidade de Coimbra, 2015. ISBN 978-989-26-1045-0. pp. 55-85.

SERVIÇO INTEGRADO DAS BIBLIOTECAS DA UNIVERSIDADE DE COIMBRA. AlmaMater. Apresentação [Em linha]. Coimbra: UC. [Consult. 31 out. 2019]. Disponível na Internet em: <https://www.uc.pt/sibuc/AlmaMater>. 